\title{
Effects of shortening and baking temperature on quality, MCPD ester and glycidyl ester content of conventional baked cake
}

\begin{abstract}
The quality of a baked product can be greatly affected by the choice of shortening. However, a palm-based shortening can be contaminated by monochlropropanol (MCPD) ester and glycidyl ester (GE) as it is a product derived from a refined palm oil. MCPD esters and GE can be transferred into a baked product through further processing. Therefore, this study aimed to evaluate the effects of different palm-based shortening on the qualities of cake, MCPD esters and GE content during a conventional baking system. Commercial margarine, palm olein, palm mid-fraction, and soft and hard stearin were used in a cake recipe, baked at different baking temperatures $\left(160,180\right.$ and $\left.200^{\circ} \mathrm{C}\right)$ for $20 \mathrm{~min}$. First, the quality characteristics of baked cake (moisture content, texture profile and surface color) was analysed. Second, the MCPD esters and GE content, acylglycerol composition and oxidation status of the fats portion from baked cake were investigated. The results showed soft stearin, palm olein and margarine delivered a similar volume, surface color, and texture to the finished product. An elevated baking temperature was detrimental to the quality characteristics of all the studied samples and delivered a finished product with extra hardness and low moisture. The free fatty acid content and specific extinction value showed that the fat portions were significantly oxidized at high baking temperatures. In addition, 2- and 3-MCPD esters were stable during baking, but GE showed that it was vulnerable to the heating process and constantly degrades when the baking temperature increased. In short, the finished products were in better quality (physical and texture properties) when lower baking temperature $\left(160^{\circ} \mathrm{C}\right)$ was used, especially when margarine, soft stearin and palm olein were used as the shortening. Hard stearin naturally contains lower MCPD esters and GE, but it was not able to provide similar qualities as compared to margarine sample.
\end{abstract}

Keyword: Food safety; Glycidyl ester; MCPD ester; Baking process; Shortenings 